\title{
A process-oriented life-cycle assessment (LCA) model for environmental and resource-related technologies (EASETECH)
}

\author{
Lodato, Concetta; Tonini, Davide; Damgaard, Anders; Astrup, Thomas Fruergaard
}

Published in:

International Journal of Life Cycle Assessment

Link to article, DOI:

10.1007/s11367-019-01665-z

Publication date:

2020

Document Version

Peer reviewed version

Link back to DTU Orbit

Citation (APA):

Lodato, C., Tonini, D., Damgaard, A., \& Astrup, T. F. (2020). A process-oriented life-cycle assessment (LCA) model for environmental and resource-related technologies (EASETECH). International Journal of Life Cycle Assessment, 25, 73-88. https://doi.org/10.1007/s11367-019-01665-z

\section{General rights}

Copyright and moral rights for the publications made accessible in the public portal are retained by the authors and/or other copyright owners and it is a condition of accessing publications that users recognise and abide by the legal requirements associated with these rights.

- Users may download and print one copy of any publication from the public portal for the purpose of private study or research.

- You may not further distribute the material or use it for any profit-making activity or commercial gain

- You may freely distribute the URL identifying the publication in the public portal 


\section{A process-oriented life-cycle assessment (LCA) model for}

\section{4 environmental and resource related technologies (EASETECH)}

5

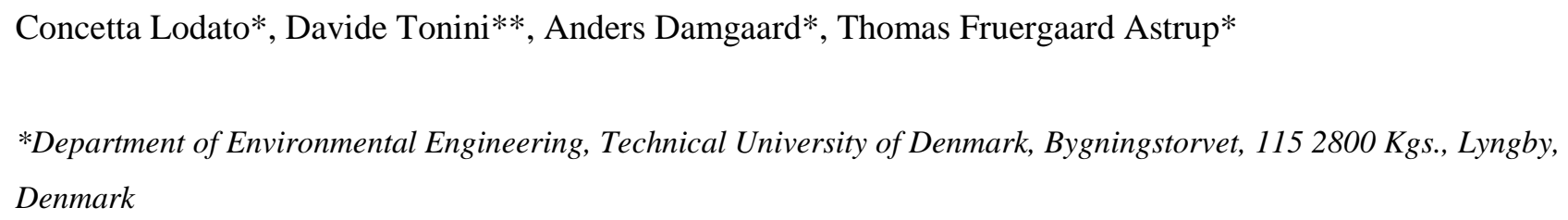

Keywords: Life cycle assessment, environmental assessment, resource recovery, technology modelling, unit-process, material flow analysis, EASETECH, biorefinery

\section{Abbreviations}

$\mathrm{CT}=$ Composite Transformer; FD = Fraction Distributor; FG $=$ Fraction Generator; FH $=$ Fraction Hub; FT $=$ Fraction Transformer; GW = Global Warming; LCA = Life Cycle Assessment; LCI = Life Cycle Inventory; MD = Material Distributor; MF = Material Flow; MG = Material Generator; NG = natural gas; RED = Renewable Energy Directive; RF $=$ Residues Flow; SD = Substance Distributor; $\mathrm{SG}=$ Substance Generator; $\mathrm{SH}=$ Substance Hub; $\mathrm{ST}=$ Substance Transformer.

“NOTE: this is the author's version of a work that was accepted for publication in The International Journal of Life Cycle Assessment. Minor changes may have been made to this manuscript since it was accepted for publication. A definitive version is published in The International Journal of Life Cycle Assessment, 1-16. https://doi.org/10.1007/s11367-01901665-z" 
In life cycle assessment (LCA), environmental technologies are often modelled as "black-box processes", where inputs and outputs are typically not linked through physical and/or (bio)chemical relationships. This limits transparency and usability of environmental modelling of resource systems for which the conversion of materials and chemical substances in the materials is essential for the environmental performance. We introduce an advanced "process-oriented" modelling framework allowing quantitative and parameterised physical-chemical relationships between input-material composition, conversion process units, and subsequent output-products, promoting mass and substance balanced conversion modelling and environmental assessment.

\section{Methods}

A dedicated LCA-model, EASETECH, has been used to provide a user-friendly platform for performing advanced LCA of complex technologies, without the need for additional software/tools. In the modelling framework, the technology is subdivided into individual unit-processes. In each process, the characterization of the input-feedstock material into biochemical, physical, chemical, and nutritional properties is taken into consideration in each multi-output production flows. For each unit-process, the processes governing the mass/energy/substance transition and transformation are described by mathematical equations (i.e. relationships between inputs and outputs) through the use of parameters. A range of new operators was developed to establish these relationships that allow for non-linear responses whereby changes in one flow, can give a non-linear response in other flows. The modelling framework and the involved operators are explained and applied to a biorefinery case-study.

\section{Results and discussion}

The model facilitates "tracking" of the feedstock material properties from the input to the final products, by establishing mass, substance and energy balances for each conversion unit-process. In addition, the process-oriented modelling framework appropriately represents material/substance transition and transformations. The choice of process parameters has considerable importance for the overall results. This was illustrated by one-at-a-time changes in parameter values in two different biorefinery unit-processes (i.e. hydrolysis, and fermentation and distillation). In addition, the relevance of feedstock characteristics for the performance of the individual unit-processes was proved with fixed parameter sets with different feedstocks. The biorefinery case-study demonstrated that the LCA model can be applied to technology cases with different process configurations (e.g. different efficiencies) and different input-feedstock properties, where it automatically adjusts to these changes in properties.

\section{Conclusions}

The advanced process-oriented modelling framework offers more flexible modelling of the conversion technology than previously available, improved options for technology development in view of environmental performance, and potentially more accurate results. This provides a significantly improved basis for environmental modelling and decisionmaking in relation to resource systems. 
Life cycle assessment (LCA) represents a standardised and systematic methodology for assessing the environmental performance of technologies and technology systems (ISO 2006 a, b; EC-JRC 2010). In the transition to a more resource efficient and sustainable society, e.g. represented by circular (bio)economy initiatives (European Commission 2014; Zabaniotou 2018) and the European sustainability targets (e.g. European Parliament and the Council of the European Union 2009), appropriate management and utilisation of waste materials and residual resources in society are critical in order to minimise losses, maximise environmental savings and avoid suboptimal solutions at societal level. Waste and residual resources represent complex and heterogeneous materials with a wide range of physical and (bio)chemical properties. Recovery and conversion of such materials into secondary raw materials and new valuable products rely on the specific characteristics of these materials, and the environmental benefits associated with potential management solutions are highly affected by the material properties themselves (Bisinella et al. 2017). LCA modelling of residual resource systems, therefore, should not only account for the resource characteristics but also reflect relationships between input-material properties and the output-products for a wide range of different conversion technologies and process configurations. This puts considerable demands on LCA modelling of resource systems to ensure transparency and flexibility in modelling.

A wide range of (non)commercial LCA-models is available for environmental assessment (e.g. SimaPro, Thinkstep Gabi, TEAM, Umberto NXT LCA; for a more complete list see EPLCA, 2019). While most of these modelling tools are primarily targeted environmental assessments of products and manufacturing, rather than systems comprising several technologies involving material flows and conversion of material resources through physical, chemical, and biological processes, the majority of these tools follow a so-called "black-box" modelling approach where embedded data inventories represent individual technologies with a fixed list of inputs and outputs. This means that the user is limited to the technology assumptions "embedded” in the inventories. As differences in modelling assumptions (e.g. technical assumptions, technology type and the inventories used) lead to differences in LCA results (e.g. Gentil et al. 2010), this is a crucial aspect that has particular importance in relation to resource systems and when the technologies themselves are in focus (e.g. Astrup at al. 2018; Henriksen at al. 2018). A few LCA-models are specifically designed to evaluate material and resource flow systems (e.g. Jain et al. 2015), with EASETECH being a notable example for LCA of environmental technologies (Clavreul et al. 2014). Using principles from material flow analysis (MFA), EASETECH keeps track of mass, substance and energy flows throughout a system of processes and technologies represented by a scenario (Clavreul et al. 2014). However, EASETECH is focused on modelling of linear material and substance flows, but does not allow accounting of interactions between individual materials and substances nor the transformation of substances themselves. This interaction is needed in case of technologies involving conversion of substances and materials, and where flows and transformations are linked to the amount of specific materials entering a process. As such, there is a need for LCA modelling frameworks allowing constraints, non-linear relationships, and new substances to be created as a result of biological and chemical reactions, while maintaining the overall mass, substance and energy balance of the model.

Black-box models can be defined as a combination of one or more single-operation unit-processes aggregated into a fixed list of inputs (energy, materials and chemicals) and outputs (products, emissions and residues) with no direct relationship between inputs, outputs and process operations (EC-JRC 2010). The evolution from product LCA to process LCA has taken time seeing the process as black-box, thus limiting the analysis of unit-processes within complex systems (Jacquemin et al. 2012). Recently, this challenge has been highlighted by Maes et al. (2015) who explained how black- 
box modelling approaches present considerable limitations to application of the EU renewable energy guidelines (European Parliament and the Council of the European Union 2009) when applied on complex production sites, mainly because black-box models cannot appropriately represent the individual unit-processes and therefore do not identify the impacts associated with these unit-processes. For resource conversion technologies such as biorefineries, this means that no specific links exist between the input-feedstock composition, the subsequent transformation of feedstock properties occurring within the individual unit-processes, and the final outputs and emissions from the biorefinery. This is in contrast to real processes in which all these aspects are directly interlinked. As such, the LCA models cannot account for potential changes in feedstock-composition between case-studies, nor for changes in performance of the involved unit-processes. Limiting LCA models to fixed technology aggregations and inventory data, thereby significantly limits the applicability of the LCA model, but also reduces the transparency of the model and requires new inventory datasets to be developed for each case-study.

To overcome the need for implementing inventory datasets according to the specific technological, geographical and temporal scope of an assessment, several approaches have been applied in literature: a) relatively simple material flow analysis (MFA) methods for determination of material flow and emission partitioning within technologies and across a system of technologies (e.g. Mancini at al. 2015; Turner at al. 2016), and b) more advanced process simulation tools (e.g. ASPEN, ProSim, ProMax, CHEMCAD) to evaluate individual biological, physical, and chemical unit-processes within a technology (e.g. Tumilar et al. 2016). While these approaches and tools certainly have merits, the definition of the technology inventories remains separated from the LCA modelling itself. A few studies (e.g. Arora et al. 2016; Brunet et al. 2012; Gaha et al. 2018) have attempted to combine LCA modelling with the process simulation tools mentioned above and/or with mathematical programming tools (e.g. MATLAB). While this potentially allows a more detailed process-oriented approach (as opposed to black-box datasets), these models are typically not integrated with the LCA tool and need to be run separately, often requiring specific insights in the programming itself (i.e. limited user-friendliness) (Asprion and Bortz 2018). While such integration is desirable, so far, we are not aware of tools that allow modelling of unit-processes of complex technologies and concurrently performing a full LCA.

To further advance and facilitate LCA-modelling of more complex and integrated resource management technologies and systems, LCA-models should allow the establishment of quantitative relationships between inputfeedstock composition, unit-processes, and subsequent outputs of products and emissions. This means “opening-up” the black-box models and allows the definition of useful relationships between inputs, outputs and process configurations. While subdivision of complex technologies into unit-processes is supported by current LCA guidelines (EC-JRC, 2010), such a modelling approach is here termed "process-oriented" LCA modelling. Modelling of residual resource technologies like biorefineries requires detailed data of the input-material (e.g. water content, energy content), the transformations of materials or substances during processing, and the transition of mass from one flow to another. To enable transparent and flexible adjustment of the model to a specific case-study, the involved model parameters should reflect subdivision in relevant unit-processes (e.g. for a biorefinery: pre-treatment, hydrolysis, fermentation and distillation, separation and recovery of the solid and liquid fractions). In an integrated technology system with several flows associated to multiple product-outputs, working with parameterised unit-processes and input-output process relationships allows to change a specific production-flow and have a non-linear response in other flows such as increasing or decreasing their production and associated emissions. Currently, no existing publically available LCA model offers 
such process-oriented modelling approach relevant for resource-centric technologies and systems, although some models enable interaction with external software to allow users some degree of taking these aspects into account.

The aim with this study is to advance LCA modelling of integrated technologies and technology systems targeting environmental assessment of resource management by implementing advanced “process-oriented” LCA modelling. The following specific objectives are addressed: i) provide a framework for process-oriented LCA modelling of multi-output conversion technologies, ii) define the needed operators and implement these in the software EASETECH, iii) demonstrate the applicability of the modelling framework on a simplified biorefinery case-study, focusing on global warming impacts in combination with the importance of feedstock characteristics and unit-process parameters (e.g. conversion efficiency) under specific operating conditions, and finally on this basis iv) evaluate the perspectives and implications of the proposed advanced process-oriented modelling approach. The outcome of the study represents the methodological basis for advanced mass, substance and energy balanced LCA modelling to resource technology systems in EASETECH.

\section{Material and methods}

\subsection{Principles of process-oriented LCA modelling}

The characterization of the input-feedstock into individual fractions, each with associated biochemical, physical, chemical, and nutritional properties is the point of departure of a process oriented LCA. Subdividing a material flow according to properties enables modelling of the conversion (or "fate") of these properties within a specific process, technology or an entire system of several technologies, and linking the input-feedstock to the associated outputs generated by the involved processes. These material properties thereby represent an extension of the substances used within MFA (Allesch and Brunner 2015; Brunner and Rechberger 2016), e.g. carbon is a chemical element and cellulose is a compound; both of them are properties of the biomass feedstock: the carbon content takes into consideration the carbon content of cellulose, representing a part of the total carbon in the biomass. Conversion of the input-feedstock is associated with either transition or transformation of feedstock properties. Transition occurs when a specific amount of a material or fraction or substance (and thereby share of material properties), usually expressed in percentages, is transferred from an input to an output of a process. The transition within a process can be partial (less than 100\% of a material flow is transferred) or total when the entire material flow is transferred. Transformation of the input-feedstock material occurs when one or more fractions or one or more substances has a change in its composition within a process. Thus, some fractions/substances may cease to exist, while new ones may be introduced. Also, in this case, the transformation can be total, when a fraction or substance is entirely used in a transformation, or it can be partial when only a defined quantity of a selected substance/fraction is involved in the conversion process. Consequently, the original material prior to the transformation does not exist anymore because a different material is generated departing from it; however maintaining the overall mass, energy and substance balance of the process. Moreover, mass transition and transformation within a system are linked to environmental exchanges that subsequently are converted into environmental impacts. For example, in a process where mass and energy are given by the material conversion of the process itself, considering emission factors during the characterisation phase (after the inventory), allows emissions to be quantified according to the availability of the substance/mass/energy involved in different material flows within the considered unit-process. In addition, in the process-oriented model, the technology is subdivided into individual unit-processes. For each unit-process, the 
(bio)physical processes governing the mass/energy/substance transition and transformation are identified and described by mathematical equations. These equations allow the establishment of relationships and interdependencies between the input-feedstock material properties and the (unit)process outputs. Parameters can be applied to allow adjustments of material flows and process performance to specific cases. If a parameter is in an equation, it can directly affect its result, and thus the conversion process, the substance/mass/energy flow, and the respective emission. Furthermore the proposed framework allow for non-linear responses whereby changes in one flow, can give a non-linear response in other flows.

Fig. 1 illustrates the generic black-box vs process-oriented technology modelling: in the black-box modelling approach (Fig. 1a), the technology is described by an input and several outputs represented by Input $t_{1}$, the products $\mathrm{P}_{1}, \mathrm{P}_{2}$, $\mathrm{P}_{3}$ and the emission $\mathrm{E}_{1}$.

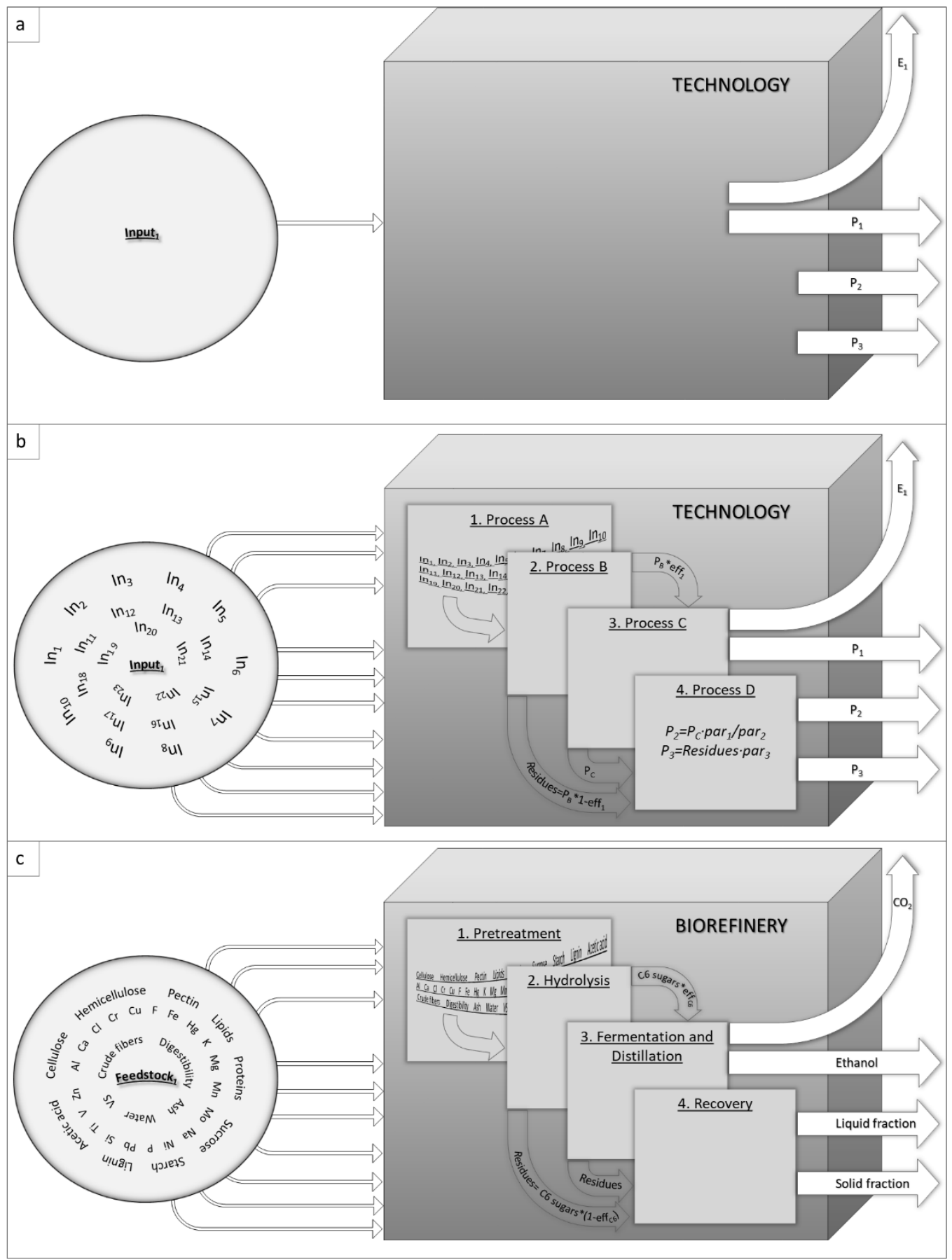


Fig. 1 a) Black-box modelling approach applied to a generic technology; Input 1 is the input-process; $P_{1}, P_{2}$ and $P_{3}$ are the output-products and $E_{1}$ is an example of technology emission.

b) Process-oriented approach applied to the same generic technology; same input, final output-products and emission (i. e. Input $1, P_{1}, P_{2}, P_{3}, E_{1}$ ); the input-properties (e.g. $\left.I n_{1}, I n_{2}\right)$ are considered. In addition, relationships/interdependencies are established between the technology unit-processes (i. e. Process $A, B, C, D$ ) and described with equations containing parameters (Equation 1: $P_{2}=P_{A 2} \cdot$ par $_{1} /$ par $_{2}$ and Equation 2: $P_{3}=P_{B 1} \cdot$ par $_{3}$, with par $_{1}$, par2 and par3 as parameters).

c) Process-oriented approach applied to the case of a second generation biorefinery. The unit-processes considered are: 1. Pretreatment, Hydrolysis, Fermentation and distillation, Recovery. The input is Feedstock $k_{1}$, having properties (e.g. Cellulose, Ca). Relationships/Interdependencies are described through equations with parameters; the final wholesystem output-products are: ethanol, liquid fraction, and solid fraction. $\mathrm{CO}_{2}$ represents an example of emission

Any relationships and interdependencies between the input-feedstock material and the output-products are not represented by the model. In addition, the technology is not subdivided into unit-processes and relationships/interdependencies represented by equations containing parameters are not included. On the contrary, in the process-oriented modelling approach the technology (Fig. 1b) is described through input-feedstock material properties (e.g. $I n_{1}, I n_{2}, I n_{3}$ ), relevant unit-processes (Process $A, B, C, D$ ), and relationships between input-feedstock material properties and process outputs using equations with parameters. In Fig. $1 \mathrm{~b}$, the output-product $\mathrm{P}_{\mathrm{B}}$ is partially transferred to Process C, i.e. $\mathrm{P}_{\mathrm{B}}$ has an associated conversion efficiency $\left(e f f_{1}\right)$ in the transition from Process B to C. (1-eff $)_{1}$ represents what is left, i.e. residue, of $\mathrm{P}_{\mathrm{B}}$ subsequently transferred to Process $\mathrm{D}$. An example of total transition is represented by the product $\mathrm{P}_{\mathrm{C}}$, totally transferred to process $\mathrm{D}$ together with the residues of Process $\mathrm{B} . \mathrm{P}_{2}$ and $\mathrm{P}_{3}$ are two products of Process D generated through two equations $\left(P_{2}=P_{C} *\right.$ par $_{1} /$ par $_{2} ; P_{3}=$ Residues $*$ par $\left._{3}\right)$. These equations are two examples of relationships between inputs and outputs within Process $\mathrm{D}$ and par $_{1}$, par $_{2}$, and $p a r_{3}$ are the three associated parameters. As an example, Fig. 1c illustrates this modelling approach implemented on a second generation biorefinery where the lignocellulosic input-feedstock is converted into bioethanol, a solid and liquid fraction, and $\mathrm{CO}_{2}$. The feedstock is characterised according to relevant biochemical, chemical, physical, and nutritional properties (e.g. cellulose, proteins, carbon content, energy content, water content, digestibility, etc.). The overall biorefinery technology is represented by a range of unit-processes: 1) pre-treatment, 2) hydrolysis, 3) fermentation and distillation, and 4) recovery. In the entire biorefinery system, both transitions and transformations occur, and the relationships between the input-feedstock properties and the output-products are identified and described by appropriate equations involving adjustable parameters (e.g. conversion efficiency of $\mathrm{C} 6$ sugars, eff $\mathrm{C}_{\mathrm{C}}$, into ethanol production, thereby facilitating flexible adaption of the model from one case-study to another). An example of material transformation is given by the hydrolysis, where polysaccharides, such as cellulose, pectin, hemicellulose, starch, and sucrose, are converted into simple sugars with five and six carbon atoms (C5 and C6 sugars). While one substance (polysaccharides) thereby is transformed into another substance (monosaccharides) and thus cease to exist, the overall mass and substance balance of the technology is maintained and the flows are trackable. In Online Resource (Sections S2 to S6), these biorefinery-unit processes are thoroughly described including the transformation equations used.

The process-oriented modelling approach allows users to establish models with all the necessary unit-processes involved, to clearly define the feedstock conversion and to include appropriate modelling parameters and assumptions. This is useful particularly in studies that wish to base the assessment on pre-developed models reproducing specific 
technologies such as lignocellulosic biorefineries, but intend to apply case-specific process performance data and/or update the model to reflect assumptions more relevant for the case-study in question.

\subsection{EASETECH modelling features supporting process-oriented modelling}

To facilitate process-oriented LCA modelling in EASETECH, a range of new "operators" were developed following the principles of domain specific language illustrated in Zarrin and Baumeister (2014). The new operators allow a domain expert (a person with the relevant technological and systemic expertise) to establish the relationships between input and output for the individual unit-processes, described in the previous section. In EASETECH, LCA scenarios are characterised by a number of "process modules" that are connected with arrows indicating material flows between the processes (see Section 2.3 for further details). Process modules may represent individual unit-processes or entire technologies and can be nested, i.e. a number of "unit-process modules" may be "packed" into another process module. As such, the scenario building in EASETECH follows the overall principles of MFA; for details see (Clavreul et al. 2014) and (Allesch and Brunner 2015). These principle are also applied to the unit-processes modelled involving the new operators and subsequently implemented into EASETECH. Tab. 1 provides an overview of all new operators, while the remainder of this section explains the key features of the operators. Further details describing the individual operators applied for the modelling of the biorefinery case study (see also Section 2.3) unit-processes can be found in Online Resource, Sections S2.7, S3.1, S4.1, S5.1 and S6.1.

Tab. 1 Operators available in EASETECH and their application for the modelling of processes within technologies and systems

\begin{tabular}{|c|c|}
\hline OPERATOR & APPLICATION \\
\hline Material Flow [MF] & $\begin{array}{l}\text { MF transfers material from a source element to } \\
\text { a target element. It is allowed using more than } \\
\text { one MF from the same source element. }\end{array}$ \\
\hline Residues Flow $[R F]$ & $\begin{array}{l}\text { RF transfers what is left in a source element } \\
\text { (residue). It is allowed using only one RF from } \\
\text { the same source element }\end{array}$ \\
\hline Fraction Distributor [FD] & FD extracts a fraction from a material \\
\hline Fraction Generator [FG] & FG generates a fraction in a material \\
\hline Fraction Hub [FH] & FH groups fractions from an input-material \\
\hline Fraction Transformer [FT] & $\begin{array}{l}\text { FT transforms a fraction into another one } \\
\text { within a material. As a consequence, the } \\
\text { previous fraction does not exist anymore }\end{array}$ \\
\hline Material Distributor [MD] & MD extracts a material \\
\hline Composite Transformer [CT] & $\begin{array}{l}\text { CT groups more than one operator. It allows } \\
\text { iterating a sequence of transformations and } \\
\text { transitions }\end{array}$ \\
\hline Primitive Parameter & It generates a parameter (numeric or string) \\
\hline Data Table Parameter & $\begin{array}{l}\text { It generates a table of parameters; it may } \\
\text { contain one or more Data Columns }\end{array}$ \\
\hline Data Column & $\begin{array}{l}\text { It generates columns into a Data Table } \\
\text { Parameter; each column refers to a parameter }\end{array}$ \\
\hline Material Generator [MG] & $\begin{array}{l}\text { MG generates a material that may contain one } \\
\text { or more material fractions }\end{array}$ \\
\hline Input & It contains all the initial inputs (starting point) \\
\hline Output & It contains all the final outputs (ending point) \\
\hline Substance Distributor [SD] & SD extracts a substance within a fraction \\
\hline
\end{tabular}




\begin{tabular}{ll}
\hline \multicolumn{1}{c}{ OPERATOR } & \multicolumn{1}{c}{ APPLICATION } \\
\hline Substance Hub $[S H]$ & SH groups substances from fractions \\
\hline Substance Transformer $[S T]$ & $\begin{array}{l}\text { ST transforms a substance into another one; } \\
\text { consequently, the previous substance does not } \\
\text { exist anymore }\end{array}$ \\
\hline Substance Generator $[S G]$ & SG generates a substance \\
\hline
\end{tabular}

The following three macro levels are considered in the model: materials, fractions and substances. Materials, following the MFA definition, contain both substances and goods. In this case, goods represent fractions, "entities” that share common characteristics, i.e. substances. As such, "grass”, "branches”, and "wood” may all represent fractions in a material called "garden waste”, while substances represent chemical, nutritional, physical and biochemical properties (e.g. cellulose, proteins, lower heating value, methane potential, digestible energy). Some of the substances may be correlated, e.g. the energy content of a fraction is a function of the content of cellulose, proteins, etc. Physical, chemical, nutritional and biochemical properties are assigned to the substance level, although they are not necessarily substances as such (e.g. energy is not a substance, but it is modelled using the same operators as for substances).

For the individual process module there is at least one input and one output. There are three possible input types: i) an output from another process, ii) a material consisting of several fractions, or iii) a single fraction. The anaerobic digestion of organic waste is an example of the first case; it generates biogas and digestate as final outputs: the digestate may then be used as input to a subsequent fertilisation process. For the second case, e.g. a material (e.g. garden waste) with multiple fractions (e.g. grass, wood), the operator that generates the input-feedstock material is Material Generator (MG); then, a Fraction Generation (FG) is needed for generating each fraction within the input-material. Thus, we are generating the material composition. The last case, when the input is a single fraction (e.g. grass), only an FG is applied to generate the fraction. Lastly, a Substance Generator (SG) is used to specify each input-material property, i.e. chemical, biochemical, physical, nutritional. Each of these properties is modelled as substances within a fraction. A range of physico-chemical relationships, represented by mathematical equations, are applied when a substance or a fraction is "transformed" within a process, e.g. one or more substances are converted into a specific product (e.g. glucose to ethanol) that may be the final output of a process or an intermediated product subsequently used in another conversion flow. The following operators are used for this purpose: Substance Transformer (ST) and Fraction Transformer (FT) when the transformation is related to a substance and a fraction, respectively. With these operators, a selected substance or fraction involved in the conversion process can be specified not to exist anymore while another substance or fraction is generated in its place, i.e. transformation from one entity into another. However, a transformation may also represent a modification of the substance or fraction content by changing only its amount while still preserving the substance or fraction itself. It is possible to change the content of a substance: the substance is the same and its amount is different (e.g. decreasing the water content of $50 \%$ of the original value).

Furthermore, each material/fraction/substance within a system or a technology may be transferred from one process to another, i.e. inter-process transition, or within a single process from inputs to outputs, i.e. intra-process transition. The inter-process transition represents cases when a process-output is transferred to a subsequent processinput, e.g. when sugars produced during hydrolysis are used in fermentation to generate ethanol and $\mathrm{CO}_{2}$, thus the transition is from hydrolysis to fermentation. The intra-process transition is when specific properties are involved in the generation of process-outputs, e.g. when in hydrolysis, cellulose is depolymerised into C6 sugars and this transition occurs 
from the hydrolysis input to the hydrolysis output. The carbon content of cellulose (here classified as a substance) contributes to the generation of C6 sugars (classified as substance). To model these two types of transitions one needs to be able to separate and "extract" a single material/fraction/substance from the remaining materials/fractions/substances.

322 Extracting means isolating the material/fraction/substance and considering it as a single independent element to be subsequently used in other conversion flows. Operators that allow this extraction are Material Distributor (MD), Fraction Distributor (FD) and Substance Distributor (SD). Considering the example of garden waste, an FD may be applied in the example where only grass (a fraction within garden waste) is addressed in a specific (unit)process. Thus, grass may be extracted from the other fractions composing the garden waste and routed to a different flow for modelling purposes. An example of using SD is the separation of non-biodegradable matter such as lignin within an organic feedstock. With SD, the lignin representing a feedstock's biochemical property may be extracted and routed to a combustion process for energy utilisation. In cases when more than one fraction or substance are routed to a new flow, these fractions and substances need to be grouped: a Fraction Hub (FH) is used for grouping fractions while a Substance Hub (SH) is for substances. Material Flows (MF) are represented by an arrow and are used for the transition of materials, fractions, and substances from a source element to a target element. Within a process, conditional statements can be associated with individual MFs, e.g. water content $>0$, to ensure a flow continues as long as the given condition is true. A Residue Flow (RF) is applied to close mass balances, i.e. to "catch" and transfer any remaining mass (residues) after transformation operations. Also, RF is represented by an arrow and is used for transitions. While it is possible to have more than one MF from a source element (e.g. an operator), only one RF can be used to close the mass balance. If the residues are transferred to a target element within the process, no other residue exists.

In addition to the above-mentioned methods to transform, divide and group materials, fractions, and substances, a range of calculations may be done on these entities by a Composite Transformer (CT). In a CT calculations may be grouped and if necessary combined with more operators relevant for the material, fraction or substance "level" in question. These calculations are performed using mathematical equations with parameters. Primitive parameters represent single values, such as a constant (e.g. conversion efficiency of C6 sugars, eff $\mathrm{C}_{6}=88 \%$ ). Data Table Parameter is used when an element has more than one parameter associated. Each column of the data table represents a parameter, i.e. the values are elements in the table, and each row is a set of parameters. The data table is identified by a name. In order to build this table, columns need to be added for each parameter; this can be done with a Data Column (DC). For each parameter (column), the value type is specified (i.e. a number or string). For example, we model cellulose that has as a parameter mass in kilograms and conversion efficiency into sugars in percentage; since it has two parameters associated, we may have a Data Table Parameter with three Data Columns, one for cellulose (substance), and a further two for the mass and the conversion efficiency. A process finishes with one or more outputs having all properties generated during the process modelling. This involves using one/more Output(s) representing all the material properties transferred to it/them through MFs and/or RFs.

An example of a combination of more than one operator described in this section is presented in Fig. 2. This represents an illustrative example removing $10 \%$ of water (substance) from the grass (fraction) in garden waste (material). A way to accomplish this is first to define and generate the material garden waste through an MG; secondly, the generation of fractions within it, such as: grass, wood, plants, branches, tree, and soil, stones and foreign objects, through FGs; thirdly, all these fractions are grouped in an FD, linked to a CT where the substances associated with each fraction are 
are sent to the final output through an RF. All the substances within grass are grouped in an SH. Water is extracted through an SD and its content is transformed (i.e. $-10 \%$ ) in an ST. In the final output, water with the different content is sent through an MF linking ST with the final output. Additionally, the other substances (with the same content) are sent to the final output through an RF from SH.

\subsection{Application of the process-oriented modelling approach to a biorefinery case}

\subsubsection{Description of the technology system}

The case-study evaluates a second generation biorefinery using the above-mentioned operators within

EASETECH. The biorefinery is composed of five main unit-processes: bio-material generation, pre-treatment, hydrolysis, fermentation and distillation, recovery. In bio-material generation, the input-feedstock is modelled considering all its properties (substances), such as biochemical (organic matter content), elemental (inorganic matter content), nutritional (i.e. the "feeding value" calculated based on the feedstock nutritional-energy content), and physical (e.g. water, ash, etc.), see Online Resource, Section S2 for details. For modelling purposes, bio-material generation is considered as a process, although this does not represent the conversion of the feedstock but merely the relevant calculations of feedstock properties prior to the input to the pre-treatment process. Some properties (e.g. dry matter, nitrogen, oxygen, 
hydrogen, carbon, sulphur, energy content, methane potential, etc.) are stoichiometrically calculated based on the biochemical and physical contents of the feedstock; as such these properties are correlated to other properties (Online Resource, Eq. S1 to S15). In the bio-material generation, mathematical equations then recalculate some of the properties of the selected feedstock, with the advantage of correlating them (e.g. C with LHV, $\mathrm{N}$ with proteins, cellulose/hemicellulose/proteins/etc. with nutritional value and LHV). All the mathematical equations used in the biomaterial composition are explained in Online Resource from Sections S2.1 to S2.6. In pre-treatment (Online Resource, Section S2), energy in the form of heat is used to pre-treat the feedstock. The structure of the lignocelluloses is broken down to separate the lignin from the cellulose and hemicellulose and allow an efficient conversion into fermentable sugars. Pre-treatment may also result in some losses (e.g. when eventual mass is lost the conversion efficiency to the pretreatment output-composition is lower than $100 \%$ ) not routed further to the hydrolysis process. In hydrolysis (Online Resource, Section S4), cellulose, starch, hemicellulose, pectin, and sucrose are hydrolysed into C5 and C6 sugars. The non-hydrolysed biochemical properties represent the hydrolysis residues. In fermentation and distillation (Online Resource, Section S5), the C5 and C6 sugars are converted to bioethanol, $\mathrm{CO}_{2}$, and liquid molasses. The unconverted sugars are transferred to yet another output and passed on to a recovery process (Online Resource, Section S6), which in addition to the fermentation residues receives the mixed solid and liquid residues from hydrolysis (hydrolysis residues); here, all residues are separated to maximise further utilisation.

Regarding the further utilisation of these output-products, the liquid fraction was assumed to be converted into biogas, while the solid fraction was assumed to be incinerated with energy recovery. For both fractions, natural gas was assumed to be substituted for simplicity. In order to focus on the technology system modelling, we deliberately neglected the possible impacts from diverting the feedstock from its current use(s) and eventual land use changes. This should be kept in mind when interpreting the results to avoid inconsistent und unfair comparisons with other studies. We briefly

\subsubsection{Assessment scope, functional unit, and system boundary}

The primary goal with the LCA was to demonstrate the applicability of process-oriented modelling in EASETECH and illustrate potential learnings that can be achieved on this basis. In this perspective, the assessment focus was placed on a single biorefinery scenario without the range of scenario alternatives and sensitivity/uncertainty evaluations otherwise part of an LCA (see Negro et al. 2017; Serra et al. 2017; Wang et al. 2016). As such, the case-study followed the principles of the relevant ISO standards (ISO 2006 a, b), while not strictly complying with these. Two perspectives were evaluated with the case-study: i) the importance of unit-process performance and choice of process parameters for the overall results, and ii) the importance of feedstock characteristics for the performance of the individual unit-processes at fixed parameter sets. For the first perspective, three types of input-feedstock were considered: wheat straw, beet top, and wild grass, while the second perspective was proved based on Miscanthus, brewer's grains, and willow. The first set of biomasses was selected based on their different composition to test the biorefinery model and the expected different results. Tab. 2 presents key characteristics and properties. The second set of biomasses was selected according to their cellulose, hemicellulose and lignin content. These three organic molecules have high importance for the carbon pool available in the biorefinery; Miscanthus has the highest cellulose content, brewer's grain has the highest hemicellulose content, and willow has the highest lignin one. 
436 Tab. 2 Characteristics and properties of wheat straw (feedstock 1), wild grass (feedstock 2) and beet top (feedstock 3), used as feedstock 437 for the biorefinery case-study

\begin{tabular}{|c|c|c|c|c|c|c|}
\hline \multicolumn{7}{|c|}{ Bio_material_generation - PARAMETERS } \\
\hline $\begin{array}{c}\text { Subgroup } \\
1\end{array}$ & $\begin{array}{l}\text { BIOCHEMICAL } \\
\text { PROPERTIES }\end{array}$ & Description & $\begin{array}{c}\text { Feedstock } \\
1\end{array}$ & $\begin{array}{c}\text { Feedstock } \\
2\end{array}$ & $\begin{array}{c}\text { Feedstock } \\
3\end{array}$ & Unit \\
\hline 1 & Acetic acid* & $\mathrm{CH} 3 \mathrm{COOH}$ & 0.0 & 0.0 & 0.0 & \%DM \\
\hline 2 & Cellulose & Cellulose parameter & 34.7 & 29.1 & 11.2 & \%DM \\
\hline 3 & Hemicellulose & Hemicellulose parameter & 22.4 & 24.2 & 16.2 & \%DM \\
\hline 4 & Lignin & Lignin parameter & 17.7 & 3.0 & 8.2 & \%DM \\
\hline 5 & Lipids & Lipids parameter & 2.3 & 0.5 & 2.4 & \%DM \\
\hline 6 & Pectin & Pectin parameter & 0.0 & 0.0 & 8.2 & \%DM \\
\hline 7 & Proteins & Proteins parameter & 3.5 & 5.2 & 16.9 & \%DM \\
\hline 8 & Starch & Starch parameter & 0.0 & 0.0 & 3.6 & \%DM \\
\hline 9 & Sucrose & Sucrose parameter & 0.0 & 0.0 & 11.9 & \%DM \\
\hline 10 & OtherVS & $\begin{array}{l}\text { Unspecified VS } \\
\text { parameter }\end{array}$ & 14.07 & 33.86 & 4.9 & \%DM \\
\hline
\end{tabular}

\begin{tabular}{|c|c|c|c|c|c|c|}
\hline $\begin{array}{l}\text { Subgroup } \\
2\end{array}$ & ELEMENTAL PROPERTIES & & & & & \\
\hline 11 & Al & Aluminium & 0.0168 & 0.0000 & 0.0000 & \%DM \\
\hline 12 & $\mathrm{Ca}$ & Calcium & 0.2435 & 0.5500 & 1.3000 & \%DM \\
\hline 13 & $\mathrm{Cl}$ & Chlorine & 0.3876 & 0.8000 & 1.6000 & \%DM \\
\hline 14 & $\mathrm{Cr}$ & Chromium & 0.0003 & 0.0000 & 0.0000 & \%DM \\
\hline 15 & $\mathrm{Cu}$ & Copper & 0.0004 & 0.0007 & 0.0013 & \%DM \\
\hline 16 & $F$ & Fluorine & 0.0011 & 0.0000 & 0.0000 & \%DM \\
\hline 17 & $\mathrm{Fe}$ & Iron & 0.0134 & 0.0220 & 0.0000 & \%DM \\
\hline 18 & $\mathrm{Hg}$ & Mercury & 0.0000 & 0.0000 & 0.0000 & \%DM \\
\hline 19 & $K$ & Potassium & 0.9870 & 0.3300 & 4.8000 & \%DM \\
\hline 20 & $M g$ & Magnesium & 0.0439 & 0.1800 & 0.4100 & \%DM \\
\hline 21 & $M n$ & Manganese & 0.0020 & 0.0070 & 0.0090 & \%DM \\
\hline 22 & Mo & Molybdenum & 0.0001 & 0.0000 & 0.0000 & \%DM \\
\hline 23 & $\mathrm{Na}$ & Sodium & 0.0100 & 0.1500 & 0.9700 & \%DM \\
\hline 24 & $\mathrm{Ni}$ & Nickel & 0.0001 & 0.0000 & 0.0000 & \%DM \\
\hline 25 & $P$ & Phosphorus & 0.0490 & 0.4000 & 0.1750 & \%DM \\
\hline 26 & $\mathrm{~Pb}$ & Lead & 0.0003 & 0.0000 & 0.0000 & \%DM \\
\hline 27 & $S$ & Sulphur & 0.0000 & 0.2100 & 0.2000 & \%DM \\
\hline 28 & $\mathrm{Si}$ & Silicon & 0.9300 & 0.0000 & 0.0000 & \%DM \\
\hline 29 & $\mathrm{Ti}$ & Titanium & 0.0005 & 0.0000 & 0.0000 & \%DM \\
\hline 30 & V & Vanadium & 0.0001 & 0.0000 & 0.0000 & \%DM \\
\hline 31 & $\mathrm{Zn}$ & Zinc & 0.0034 & 0.0000 & 0.0045 & \%DM \\
\hline $\begin{array}{l}\text { Subgroup } \\
3\end{array}$ & FEEDSTOCK & & & & & \\
\hline 32 & Fraction name & Fraction & $\begin{array}{l}\text { Wheat } \\
\text { straw }\end{array}$ & Wild grass & Beet top & String \\
\hline $\begin{array}{l}\text { Subgroup } \\
4\end{array}$ & FEEDSTOCK AMOUNT & & & & & \\
\hline 33 & Quantity & Input amount & 1000 & 1000 & 1000 & $\mathrm{~kg}_{w w}$ \\
\hline $\begin{array}{l}\text { Subgroup } \\
5\end{array}$ & NUTRITIONAL PROPERTIES & & & & & \\
\hline 34 & Crude_Fibers_input & Crude fibres parameter & 45.3 & 78 & 82 & \%DM \\
\hline 35 & Digestibility_input & Substrate digestibility & 44 & 24.9 & 12 & $\%$ DM \\
\hline $\begin{array}{l}\text { Subgroup } \\
6\end{array}$ & PHYSICAL PROPERTIES & & & & & \\
\hline 37 & Ash & Ash parameter & 5.4 & 4.1 & 16.5 & \%DM \\
\hline 38 & VS & Volatile solid parameter & 94.7 & 95.9 & 83.5 & \%DM \\
\hline 39 & Water & Water parameter & 12.2 & 78.8 & 76.7 & $\%_{\mathrm{ww}}$ \\
\hline
\end{tabular}

* Acetic acid may be present in some biomasses as degradation product 

into three main output-products: bioethanol, solid, and a liquid fraction”. While results were calculated for all the impact categories included in the IPCC 2013 method (IPCC, 20013; 100-year time horizon was assumed), only results for global warming were discussed for the purpose of illustrating the functionality and applicability of the process-oriented modelling approach. Fig.3 illustrates a generic representation of the biorefinery process-oriented model.

\section{5}

446

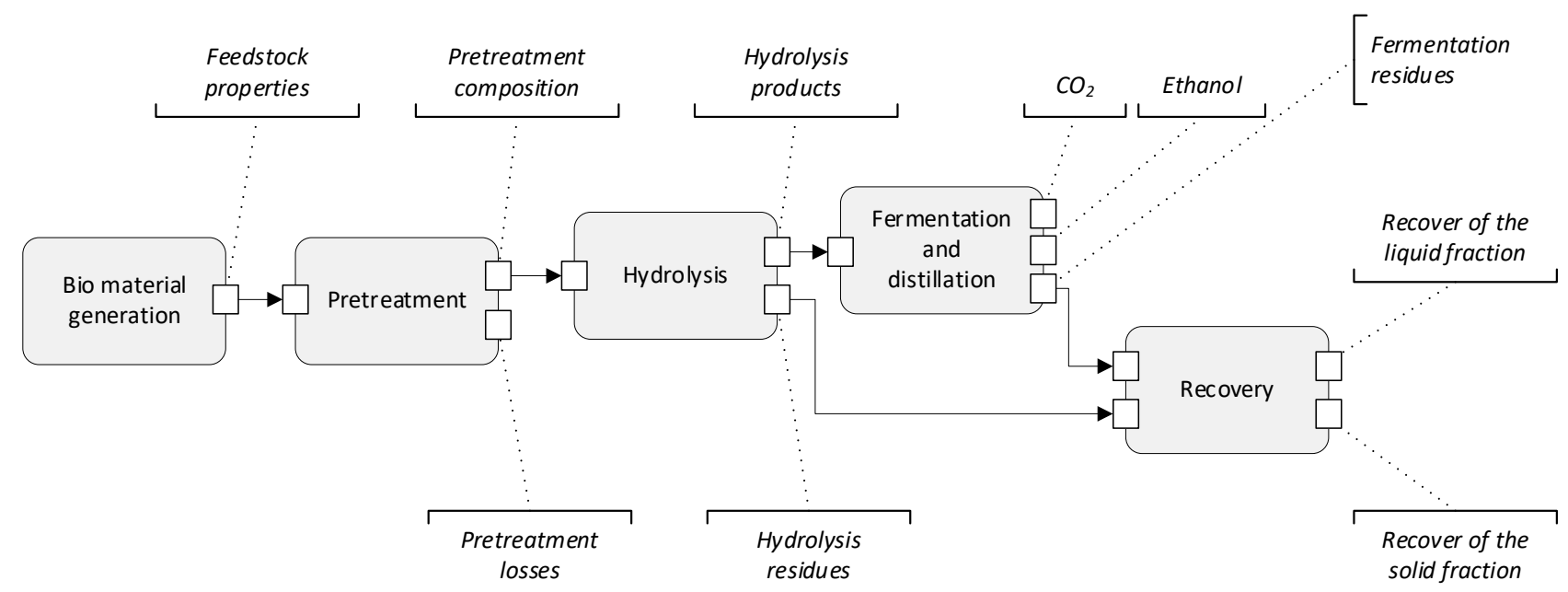

Fig. 3 Generic representation of the biorefinery process-oriented model in EASETECH with the intermediate and final outputs

To ensure simplicity, a "zero burden" approach was followed and no upstream burdens associated with the inputfeedstock biomass nor any indirect effects associated with the diversion from alternative uses of the biomass (counterfactual scenarios) were included. System expansion was applied to credit the system for avoided impacts associated with substituting and displacing conventional market products with the biorefinery output-products. Ethanol was assumed to be used in vehicles, substituting gasoline; molasses, the liquid fraction from the biorefinery, was used in a biogas plant substituting the production and combustion of natural gas; solid biofuel, the solid fraction from the biorefinery, was used in an incineration plant that substituted the production and combustion of natural gas. The emission factor assumed for gasoline was $0.097 \mathrm{kgCO}_{2}$-eq $\cdot \mathrm{MJ}^{-1}$ and the emission factor for natural gas was $0.067 \mathrm{kgCO}_{2}$ eq $\cdot \mathrm{MJ}^{-1}$ from EASETECH database (Clavreul et al. 2014). The residual digestate after biogas production was assumed to displace conventional NPK fertilizers, according to the content of N, P, and K. The substitution efficiency was assumed to be $40 \%$ for $\mathrm{N}$ according to current Danish legislation (Danish Ministry of Food, Agriculture and Fisheries 2018) and 100\% for P and K. Air and water emissions arising from digestate and mineral fertilisers (avoided) spreading on-land were based on the work of Yoshida et al. (2016); particularly, the emission factors used to describe $\mathrm{N}_{2} \mathrm{O}$ emissions from digestate and substituted mineral fertilizers were $2.78 \%$ and $(2.32 * 0.40) \%$ respectively. The system boundaries included refinery operations, harvest of biomass, transportation (digestate and solid fraction) as well as final utilisation and management of all biorefinery outputs.

\section{Results}

\subsection{Importance of unit-process operational efficiencies}


Fig. 4 presents the results of global warming (GW) in $\mathrm{kg} \mathrm{CO}_{2-\mathrm{eq}} \mathrm{t}^{-1} \mathrm{ww}$ for a biorefinery using wheat straw as 479 feedstock. The biorefinery outputs are given in ${\mathrm{MJ} \cdot \mathrm{t}^{-1} \mathrm{ww}}$ as a function of the efficiencies of the hydrolysis (Fig. $4 \mathrm{a}$ and $4 \mathrm{~b}$ ) 480 and the fermentation (Fig. 4c and 4d) unit-processes. Through the selection of parameters (e.g. yield, efficiencies, etc.), 481 the model responds to variations in the performance of the individual unit-processes and allows users to adapt a specific 482 biorefinery configuration. Here, the environmental impacts of the entire technology systems were calculated by one-at-a483 time changes in parameter values, from a low conversion efficiency (25\%) to a complete conversion (100\%). For example, 484 for fermentation of C5 sugars, only the fermentation efficiency was changed with all other parameters unchanged; the 485 parameter values ( $0 \%, 25 \%, 50 \%, 75 \%$ and $100 \%)$ were selected for illustrative purposes 


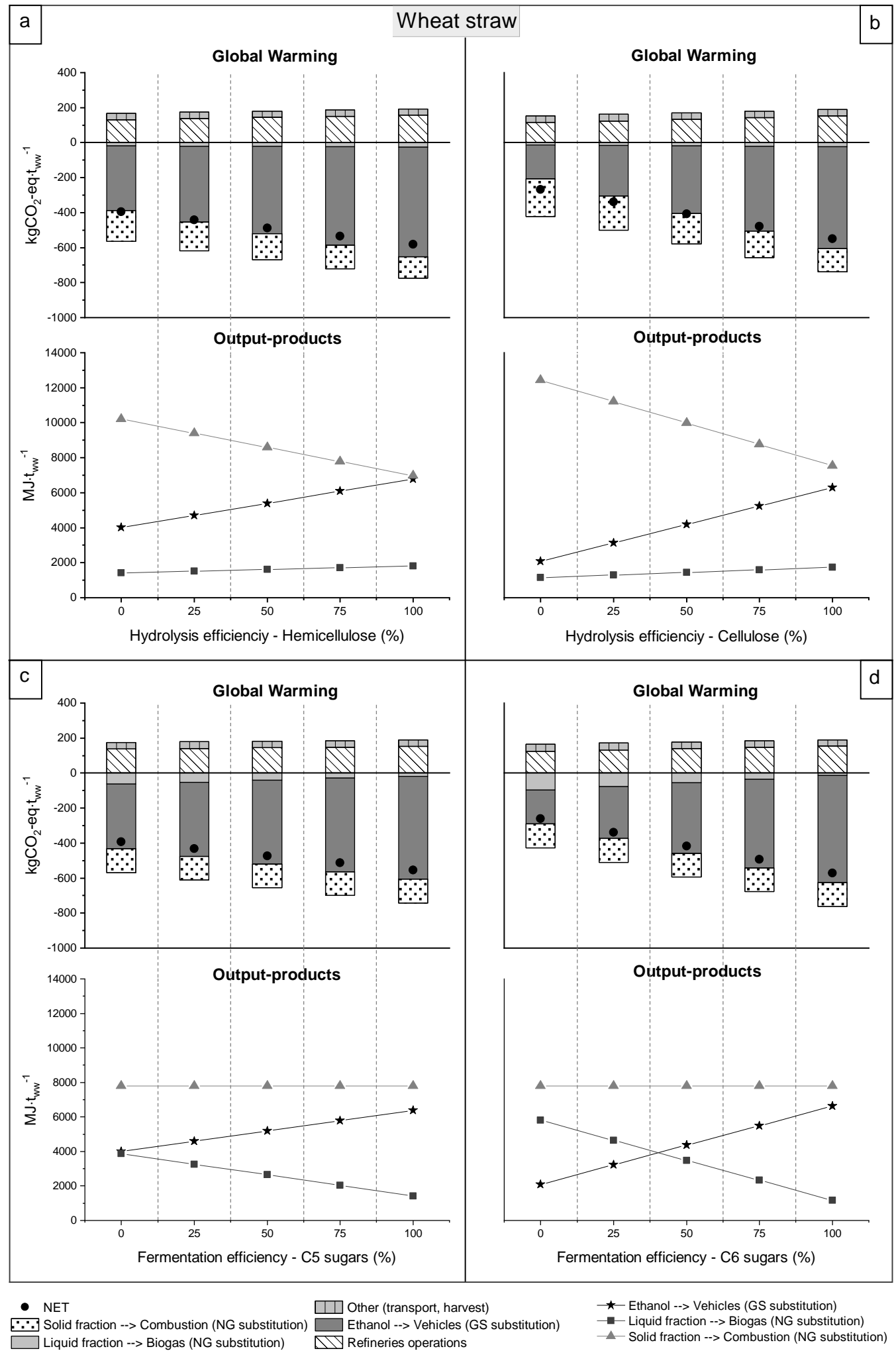

Fig. 4 An overview of the process-oriented LCA model response, in terms of global warming, GW, $\left(\mathrm{kgCO}_{2}\right.$ eq $\cdot \mathrm{kg}_{\mathrm{ww}}{ }^{-1}$ ) and mass/energy balance $\left(\mathrm{MJ} \cdot \mathrm{tww}^{-1}\right)$, to (one-at-the-time) unit-process performance variations (i.e. 0\%, 25\%; 50\%; 75\%; 100\%): 3a) hemicellulose conversion efficiency in hydrolysis, 3b) cellulose conversion efficiency in hydrolysis, 3c) C5 sugars conversion efficiency in fermentation, 3d) C6 sugars conversion efficiency in fermentation. The feedstock considered is wheat straw. NG: natural gas; GS: gasoline 
As the results demonstrate, process parameters play an important role: the user can modify the mass and energy balances (here represented by the process-outputs) with a direct effect on the associated environmental impacts (here represented by GW). In this example, increased efficiency of cellulose hydrolysis leads to better GW performance (Fig. 3b); this is reflected by the increased production of liquid fuel (ethanol) and the decreased production of solid fraction (sometimes called solid biofuel) resulting in the decreased substitution of natural gas combustion. In addition, increasing the fermentation efficiency of C6 sugars leads to better GW performance (Fig. 4d); also in this case, fuel production was increased, but now the liquid fraction (sometimes called molasses) decreased, thereby resulting in lower biogas production and lower substitution of natural gas combustion. In Fig. 4, for a cellulose hydrolysis efficiency of $0 \%$ the associated GW performance was $-269 \mathrm{~kg} \mathrm{CO} 2-\mathrm{eq} \cdot \mathrm{t}_{\mathrm{ww}}{ }^{-1}$; for an efficiency of $25 \%$, the associated GW performance was $-339 \mathrm{~kg}$ CO2eq $\cdot \mathrm{t}_{\mathrm{ww}}{ }^{-1}$; for an efficiency of $50 \%$, the associated $\mathrm{GW}$ performance equalled $-409 \mathrm{~kg} \mathrm{CO}_{2}$-eq $\cdot \mathrm{t}_{\mathrm{ww}}{ }^{-1}$, for $75 \%$ it was $-479 \mathrm{~kg}$ $\mathrm{CO}_{2}$-eq $\cdot \mathrm{t}_{\mathrm{ww}}{ }^{-1}$ and for $100 \%$ it was $-549 \mathrm{~kg} \mathrm{CO}$-eq $\cdot \mathrm{t}_{\mathrm{ww}}{ }^{-1}$. Such direct proportionality between the energy/mass balances and the GW impacts may not necessarily have a direct effect on full scenario results as also framework conditions may be important, e.g. type of substituted energy, system boundaries, and process configurations. Furthermore the linear results are due to the equations applied in the case example, the model could just as well have been used for cases with exponential changes, or more scattered results if conditions for flow properties were applied in the model. These aspects can, however, be captured by the process-oriented LCA model either by adjusting parameters, changing the mathematical relationships involving the functions introduced earlier, or choice of background process data and interactions with the background system. For further details of the biorefinery modelling results involving variations in parameter efficiencies and associated GW impacts, please see Online Resource, Section S7, Tab. S7.1, S7.2 and S7.3.

Overall, similar results and trends were obtained for the two other feedstock types, beet top and wild grass, i.e. higher efficiencies provided larger environmental savings (see Online Resource, Section S8, Fig. S8.1 and S8.2 for the results). Differences in biochemical and physical properties between wheat straw, beet top and wild grass were reflected in the results by different "levels". With a cellulose hydrolysis efficiency of $0 \%$, the associated GW performance for beet top was $-55 \mathrm{~kg} \mathrm{CO}$-eq $\cdot \mathrm{t}_{\mathrm{ww}}{ }^{-1}$ and for wild grass $-37 \mathrm{~kg} \mathrm{CO}$-eq $\cdot \mathrm{t}_{\mathrm{ww}}{ }^{-1}$; for an efficiency of $25 \%$, the associated GW performance for beet top was $-61 \mathrm{~kg} \mathrm{CO}$-eq $\cdot \mathrm{t}_{\mathrm{ww}}{ }^{-1}$ and for wild grass $-51 \mathrm{~kg} \mathrm{CO}$-eq $\cdot \mathrm{tww}^{-1}$; for an efficiency of $50 \%$, the associated GW potential was respectively -67 and $-65 \mathrm{~kg} \mathrm{CO}_{2}$-eq $\cdot \mathrm{tww}^{-1}$, while for $75 \%$ it was -73 and $-79 \mathrm{~kg} \mathrm{CO}$-eq $\cdot \mathrm{t}_{\mathrm{ww}}{ }^{-}$ demonstrates the relative importance of the hydrolysis and fermentation steps for the three different feedstocks and thereby transparently explains the difference in results between the cases. This demonstrates that the model can be applied to technology cases with different process configurations (illustrated here by different efficiencies of unit-processes and subsequent changes in material and substance flows) and can accommodate different input-feedstock properties in a flexible manner.

\subsection{Importance of input-feedstock characteristics}

The feedstock characteristics play an important role for the biorefinery performance, both with respect to GW ( $\mathrm{kg} \mathrm{CO}$-eq $\cdot \mathrm{t}_{\mathrm{ww}}{ }^{-1}$ ) and output-products (e.g. MJ $\cdot \mathrm{t}_{\mathrm{ww}}{ }^{-1}$ ) as illustrated in Fig. 5. 

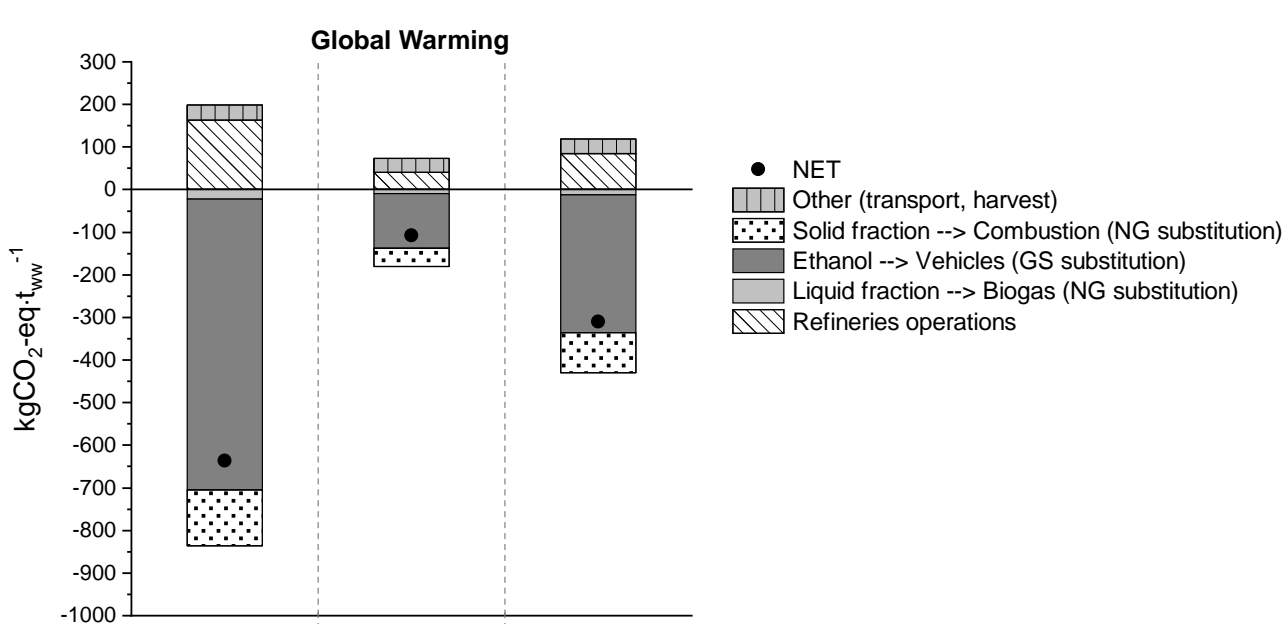

$-800$

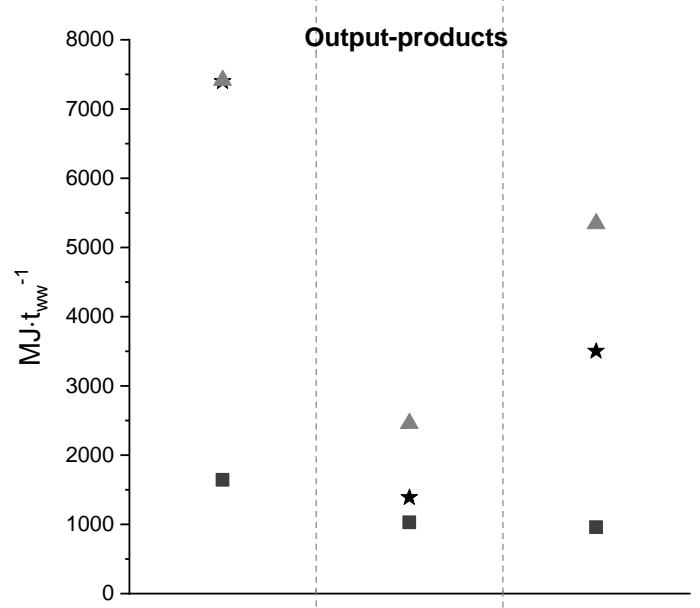

Ethanol --> Vehicles (GS substitution)

- Liquid fraction --> Biogas (NG substitution)

- Solid fraction --> Combustion (NG substitution)

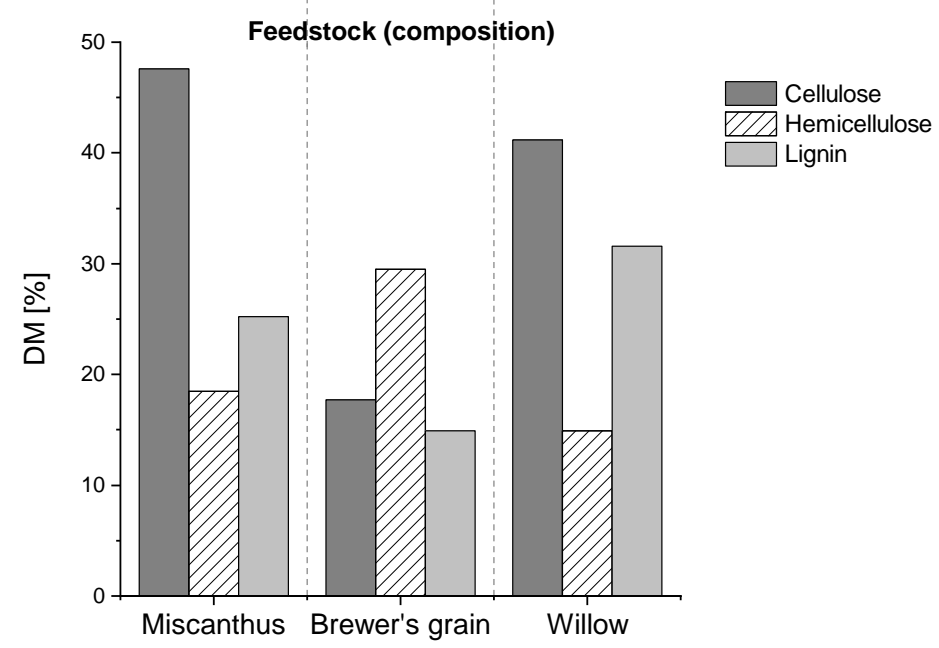

Fig. 5 Process-oriented LCA model response, in terms of global warming, GW, ( $\left.\mathrm{kgCO}_{2}-\mathrm{eq} \cdot \mathrm{kg}_{\mathrm{ww}}{ }^{-1}\right)$ and mass/energy balance $\left(\mathrm{MJ} \cdot \mathrm{tww}^{-1}\right)$, to three different feedstocks (i.e., Miscanthus, brewer's grain and willow) having different shares of cellulose, hemicellulose and lignin. NG: natural gas; GS: gasoline. For these three biomasses the values of the parameters used are: in hydrolysis, a cellulose and a hemicellulose conversion efficiency of $95 \%$ and 75\% respectively, and in fermentation and distillation the conversion efficiency of 88\% for both C5 and C6 sugars 
Among the three biomasses addressed here, Miscanthus has the highest cellulose content ( $\mathrm{CE}=47.6$ \% ${ }_{\mathrm{DM}}$ ), brewer's grain has the highest hemicellulose content $(\mathrm{HC}=29.5 \%$ DM $)$, and willow the highest lignin content ( $\mathrm{LG}=31.6$

637 \% $)$. In Online resources, Section S9, Tab S9.1 presents key characteristics and properties of these three biomasses. The cellulose, hemicellulose, and lignin contents for these three biomasses are shown in Fig. 5. The conversion efficiencies considered were: 95\% and 75\% for cellulose and hemicellulose respectively during hydrolysis, and for both C5 and C6 sugars it was $88 \%$ during fermentation and distillation.

Considering the three main products of the biorefinery (ethanol, solid and liquid fraction), cellulose and hemicellulose affect mostly the production of ethanol and the liquid fraction as these molecules can be hydrolysed into chains of monosaccharides (e.g. glucose) used in the fermentation to produce ethanol and $\mathrm{CO}_{2}$. Lignin represents the carbon pool that in a biorefinery leads to the formation of the solid fraction output unless pretreatment is applied, together with non-hydrolysed material. With this in mind, based on the composition of the three feedstocks, Miscanthus generated more ethanol $\left(7400 \mathrm{MJ} \cdot \mathrm{tww}_{\mathrm{ww}}{ }^{-1}\right)$, followed by willow $\left(3500 \mathrm{MJ} \cdot \mathrm{t}_{\mathrm{ww}}{ }^{-1}\right)$ and brewer's grain $\left(1400 \mathrm{MJ} \cdot \mathrm{tww}^{-1}\right)$. Considering the solid fraction, although willow has the highest lignin content Miscanthus provided the largest solid fraction (7200 MJ $\cdot \mathrm{t}_{\mathrm{ww}}{ }^{-}$ ${ }^{1}$ ), due to the larger amounts of unconverted sugars (dry basis). The liquid fraction is influenced mainly by the fermentation and distillation process. For this reason, Miscanthus provided the highest liquid output $\left(1600 \mathrm{MJ}^{-\mathrm{ww}_{\mathrm{w}}}{ }^{-1}\right)$ followed by brewer's grain $\left(1000 \mathrm{MJ} \cdot \mathrm{tww}_{\mathrm{ww}}{ }^{-1}\right)$ and willow $\left(960 \mathrm{MJ} \cdot \mathrm{tww}^{-1}\right)$. In this illustrative example, the conversion of all three biomasses provided net GW savings as no upstream activities (e.g. production) and indirect effects (e.g. land-use changes) were included. The largest savings were obtained from Miscanthus due to its higher dry matter content. These results were in accordance with Parajuli at al. (2017), who showed that the high dry matter and energy yield of the inputfeedstock material can contribute to a better environmental performance. In addition, the relevance of conversion efficiencies of feedstock properties (e.g. carbohydrates) in the biorefinery processes was highlighted in Parajuli et al. (2017), in agreement with this study.

While the influence of feedstock choice on the LCA results have been evaluated previously in the literature (e.g. Bernstad Saraiva A 2017; Tonini et al. 2016 b), the above process-oriented assessment approach demonstrates the added insight of the importance of individual unit-processes (and potentially also parameter choices as illustrated in the previous section). Particularly, the inter- and intra-process transition, the material transformation due to the process specificities and the feedstock specificities (e.g. the importance of feedstock properties and their availability to be degraded or converted into different products), and their consequences in terms of environmental impacts.

\section{Discussion}

\subsection{Novel insights from process-oriented modelling}

The process-oriented approach focuses on the evaluation of process relationships through subdivisions of technologies into unit-processes and appropriate linking of process material inputs with transformation and process-outputs. In previous literature (e.g. Tonini et al. 2016 a, b), these aspects have been demonstrated as critical for the LCA results and interpretation, in particular in relation to integrated technologies such as biorefineries where the feedstock characteristics and the biorefinery outputs are interdependent and further affect the downstream substitutions (e.g. energy, feed, materials). One of the most notable advantages of the process-oriented modelling approach is the possibility of 
implementing new (unit)processes by using operators in a single modelling tool such as EASETECH, rather than requiring a combination of several tools as illustrated by previous literature (e.g. in Tonini et al. 2016 a, b, and Vadenbo et al. 2018, where a combination of Matlab, Gams, and SimaPro was applied).

Mathematical equations describing the input-output relationships are integrated within the model itself and default parameter values can be further adjusted by the users. The subdivision into unit-processes is important for identification, quantification and evaluation of intermediate process-outputs within the system. Further, the process parameters and associated mathematical relationships themselves may be selected to appropriately represent operational parameters that can be recognised by users and more easily adjusted to accommodate specific case-studies and industry data. Quantification of the intermediate products linking individual unit-processes allows evaluation of the environmental performance of these unit-processes, which may further allow identification of technology hotspots at a much more detailed level than traditional "black-box" modelling approaches, both in terms of production and emissions. This is fully in line with existing recommendations, e.g. by ILCD guidelines (EC-JRC 2010) and strongly highlighted in Jacquemin et al. (2012).

The process-oriented modelling approach enables more control of the material, energy and substance flows within the analysed technologies. This is particularly important in relation to integrated technologies such as biorefineries or many waste technologies for which intermediate products affect the subsequent processing; an aspect that black-box approaches cannot capture (Maes et al. 2015). Modelling a biorefinery technology within EASETECH following the process-oriented approach offers an "active" material flow system represented by the established input-output relationships and parameters. This material flow system is linked to environmental emissions and output-product substitutions associated with the LCA scenarios; thereby a direct link between input-feedstock composition, process operation and environmental performance is established. For example, higher hydrolysis and fermentation efficiencies incur larger ethanol production with lower solid and liquid residue quantities, thereby increasing gasoline substitution and lowering natural gas substitution. Although purposely kept simple in this illustrative case-study, interactions between the foreground and background systems can be easily modelled with appropriate selection of parameters. The conversion of biochemical properties of the feedstock into the biorefinery products depends on the type of feedstock and its degradability under the specific operating conditions of the technology. All such aspects can be addressed and evaluated by the proposed process-oriented modelling approach.

\subsection{Implications for LCA}

Subdividing the technology into relevant unit-processes and establishing appropriate input-output relationships including operating parameter variations allow a direct response of the LCA model with respect to potential environmental impacts. While subdivision into smaller units has been suggested in previous literature, this has mainly been discussed from the perspective of Maes et al. (2015) rather than with the intention of Götze et al. (2014) and Papadokonstantakis et al. (2016) as suggested here for the process-oriented approach. Only few studies have discussed the potential of establishing operational relationships and more “technology relevant” parameters (e.g. Portha et al. 2010; Kikuchi et al. 2014). As previously indicated, the ability to "track" intermediates and conversion of individual input-material fractions is essential for LCA modelling of multi-output technologies (e.g. Astrup et al. 2018), although relatively few LCA studies take this aspect seriously. With a black-box approach, where unit-processes may be combined even if they are physically separated, relevant disaggregation of the environmental impacts associated with individual outputs may not be possible 
(e.g. Jacquemin at al. 2012). As the process-oriented modelling approach attempts to disaggregate technology and process elements into individual units reflecting the actual process flow and conversion steps, the process-oriented approach can facilitate easier compliance with the recommendations provided by current ISO standards and ILCD guidelines with respect to multi-functionality. In the case of LCA modelling of material and resource technology systems, we suggest that the process-oriented approach is a needed development from black-box approaches and that these cannot be considered state-of-the-art for such systems. We envision that further development of process-oriented inventories may offer a route to avoid the current challenges of multi-functionality associated with complex multi-output technologies.

LCA studies are also sometimes used to assess the environmental performance of technologies prior to commercialisation and full-scale implementation, e.g. prospective assessment of emerging technologies (Arvidsson et al. 2017). From a black-box modelling perspective, such assessments pose specific challenges with respect to data uncertainties, process configurations, potential performance improvements, etc. as these aspects are typically aggregated within the technology inventory thereby limiting transparency. Process-oriented modelling, on the other hand, allows disaggregation and establishment of appropriate data relationships. Thereby the uncertainties and importance of individual process parameters may be evaluated directly and linked to the environmental performance of the technology in question. This makes process-oriented modelling particularly relevant for LCA assisted technology developments and upscaling activities, as the assessment results allow identification of process hotspots that may otherwise remain un-evaluated. We envision that these aspects are particularly important in relation to integrated and multi-output technologies as part of circular (bio)economy initiatives.

\subsection{Further research and perspectives}

As developed and implemented in this study, the process-oriented modelling approach represents a first attempt to demonstrate applicability and potential. Future research is intended to focus on improving the existing model and extending the process-oriented modelling approach to a wide range of material-centric technologies, e.g. anaerobic digestion, thermal pyrolysis and gasification, thermal combustion, and biomaterial production facilities. This requires identification and appropriate implementation of relevant process relationships between input-resources and materials (e.g. chemicals, energy, etc.) and process-outputs and emissions. While EASETECH offers a unique basis for this as the modelling is already based on material flows, implementation of new process-oriented technology models nevertheless requires considerable effort (see Online Resource as an example for a biorefinery). However, once a process-oriented model is established, subsequent adjustments can be achieved simply by changing the appropriate parameters (assuming the fundamental process configuration remains appropriate). As mentioned earlier (section 2.3.1), to focus on the technology modelling, we deliberately excluded the upstream impacts associated with diverting the feedstock from its current use(s) or with land use changes. Such impacts have been earlier estimated in the order of $19-88 \mathrm{~kg} \mathrm{CO}_{2}$-eq $\cdot \mathrm{t}_{\mathrm{ww}}{ }^{-1}$ for wild grass and wheat straw, 191-360 $\mathrm{kg} \mathrm{CO}-\mathrm{eq} \cdot \mathrm{t}_{\mathrm{ww}}{ }^{-1}$ for perennial energy crops as willow and Miscanthus, and 265$287 \mathrm{~kg} \mathrm{CO}$-eq $\cdot \mathrm{t}_{\mathrm{ww}}{ }^{-1}$ for agro-industrial residues as beet top and brewer's grain (Tonini et al $2016 \mathrm{a}$, b). These figures should be added to the results quantified in this study to obtain a full picture of the Climate Change impact of the studied scenarios.

\section{Conclusion}



this in EASETECH and applied this on a biorefinery case-study for illustrative purposes. The process-oriented modelling

751 framework provides an improved representation of complex technologies allowing definition and evaluation of process 752 relationships between inputs and outputs. This is particularly important for integrated technologies comprising individual 753 unit-processes, e.g. biomass conversion and management of residual resources. Traditional black-box modelling 754 approaches, represented by most existing LCA models, do not offer similar possibilities for detailed evaluation of 755 processes and technologies nor allow the same level of transparency with respect to inventory definition. The process756 oriented modelling framework provided by this study allows consistent balancing of material, fraction, and substance 757 flows within the technology system and, through mathematical expressions, at the same time establishment of the process 758 relationships that affect these flows through transition and transformation within each single unit-process. Based on the 759 biorefinery case-study, the advantages of the modelling approach were demonstrated: input-feedstocks and key process 760 operational parameters can be adjusted easily in order to evaluate process performance and the importance of feedstock 761 properties. This facilitate quantification of individual/intermediate (bio)product flows within unit-processes; this has not 762 been possible previously. The potential implications of process-oriented modelling are considerable, e.g. in relation to 763 novel insights associated with uncertainty evaluation, technology upscaling and process optimisation.

\section{Acknowledgements} 0044).

\section{Conflict of interest}

The authors declare that they have no conflict of interest. 


\section{References}

Allesch A, Brunner PH (2015) Material Flow Analysis as a Decision Support Tool for Waste Management: A Literature Review. J Ind Ecol 19:753-764. doi: 10.1111/jiec.12354

Arora P, Hoadley A, Mahajani S, Ganesh A (2016) Multi-level Modelling of Sustainable Chemical Production: from CFD to LCA. In: Computer Aided Chemical Engineering. Elsevier Masson SAS, pp 499-504. https://doi.org/10.1016/B978-0-444-63428-3.50088-6

Arvidsson R, Tillman A-M, Sandén BA, et al (2017) Environmental Assessment of Emerging Technologies: Recommendations for Prospective LCA. J Ind Ecol 00:1-9. doi: 10.1111/jiec.12690

ASPEN (2019). https://www.aspentech.com/ (accessed 12 February 2019)

Asprion N, Bortz M (2018) Process Modeling, Simulation and Optimization: From Single Solutions to a Multitude of Solutions to Support Decision Making. Chemie Ing Tech 90:1727-1738. doi: 10.1002/cite.201800051

Astrup TF, Pivnenko K, Eriksen MK, Boldrin A (2018) Life Cycle Assessment of Waste Management: Are We Addressing the Key Challenges Ahead of Us? J Ind Ecol 22:1000-1004. doi: 10.1111/jiec.12811

Bisinella V, Götze R, Conradsen K, et al (2017) Importance of waste composition for Life Cycle Assessment of waste management solutions. J Clean Prod 164:1180-1191. doi: 10.1016/j.jclepro.2017.07.013

Brunet R, Cortés D, Guillén-Gosálbez G, et al (2012) Minimization of the LCA impact of thermodynamic cycles using a combined simulation-optimization approach. Appl Therm Eng 48:367-377. doi: 10.1016/j.applthermaleng.2012.04.032

Brunner PH, Rechberger H (2016) Handbook of Material Flow Analysis. CRC Press, Taylor \& Francis Group, 6000 Broken Sound Parkway NW, Suite 300, Boca Raton, FL 33487-2742

Clavreul J, Baumeister H, Christensen TH, Damgaard A (2014) An environmental assessment system for environmental technologies. Environ Model Softw 60:18-30. doi: 10.1016/j.envsoft.2014.06.007

Danish Ministry of Food, Agriculture and Fisheries (2018) Plantedirektoratet Bekendtgørelse nr. 1008 af 02 juli 2018 om jordbrugets anvendelse af gødning og om plantedække i planperioden 2018/2019. Available at https://www.retsinformation.dk/pdfPrint.aspx?id=202375 (accessed 17 June 2019)

EC-JRC. (2010). International Reference Life Cycle Data System (ILCD) Handbook -- General guide for Life Cycle Assessment -- Detailed guidance. Constraints. https://doi.org/10.2788/38479

EPLCA (2019). European Platform on Life Cycle Assessment. List of Tools. Internet Site Developed by the European Commission. Joint Research Centre, Directorate D, Sustainable Resources. http://eplca.jrc.ec.europa.eu/ResourceDirectory/faces/tools/toolList.xhtml (accessed 12 February 2019.)

European Parliament and the Council of the European Union. (2009). Directive 2009/28/EC of the European Parliament and of the Council of 23 April 2009. Official Journal of the European Union, 140(16), 16-62. https://doi.org/10.3000/17252555.L_2009.140.eng

European Commission (2014). HORIZON 2020 WORK PROGRAMME 2014 - 2015 9. Food security, sustainable agriculture and forestry, marine and maritime and inland water research and the bioeconomy Revised. Retrieved from part_9_food_security_v2.0_en.pdf 
Gaha R, Benamara A, Yannou B (2018) Proposition of Eco-Feature : A New CAD / PLM Data Model for an LCA Tool. 763-770. doi: 10.1007_978-3-319-66697-6_74

Gentil EC, Damgaard A, Hauschild M, et al (2010) Models for waste life cycle assessment: Review of technical assumptions. Waste Manag 30:2636-2648. doi: 10.1016/j.wasman.2010.06.004

Götze U, Hertel A, Schmidt A, Päßler E (2014) Technology and Manufacturing Process Selection. Springer London, London

Henriksen T, Astrup TF, Damgaard A (2018) Linking Data Choices and Context Specificity in Life Cycle Assessment of Waste Treatment Technologies: A Landfill Case Study. J Ind Ecol 22:1039-1049. doi: 10.1111/jiec.12709

IPCC. (2013) Climate Change 2013: The Physical Science Basis. Contribution of Working Group I to the Fifth Assessment Report of the Intergovernmental Panel on Climate Change [Stocker, T.F., D. Qin, G.-K. Plattner, M. Tignor, S.K. Allen, J. Boschung, A. Nauels, Y. Xia, V. Bex and P.M. Midgley (eds.)]. Cambridge University Press, Cambridge, United Kingdom and New York, NY, USA, 1535 pp, doi:10.1017/CBO9781107415324

ISO. (2006 a). Environmental management - Life cycle assessment - Requirements and guidelines - ISO 14044. Geneva.

ISO. (2006 b). Environmental management - Life cycle assessment - Principles and framework - ISO 14040. Geneva.

Jacquemin L, Pontalier P-Y, Sablayrolles C (2012) Life cycle assessment (LCA) applied to the process industry: a review. Int J Life Cycle Assess 17:1028-1041. doi: 10.1007/s11367-012-0432-9

Jain, P., B. Dyson, T. M. Tolaymat WI (2015) A Comparative Analysis of Life-Cycle Assessment Tools for End-of-Life Materials Management Systems. U.S. Environmental Protection Agency, Washington, DC, EPA/600/R-15/232

Kikuchi Y, Kimura S, Okamoto Y, Koyama M (2014) A scenario analysis of future energy systems based on an energy flow model represented as functionals of technology options. Appl Energy 132:586-601. doi: 10.1016/j.apenergy.2014.07.005

Maes D, Van Dael M, Vanheusden B, et al (2015) Assessment of the sustainability guidelines of EU Renewable Energy Directive: the case of biorefineries. J Clean Prod 88:61-70. doi: 10.1016/j.jclepro.2014.04.051

Mancini L, Benini L, Sala S (2015) Resource footprint of Europe: Complementarity of material flow analysis and life cycle assessment for policy support. Environ Sci Policy 54:367-376. doi: 10.1016/j.envsci.2015.07.025

Negro V, Ruggeri B, Fino D, Tonini D (2017) Life cycle assessment of orange peel waste management. Resour Conserv Recycl 127:148-158. doi: 10.1016/j.resconrec.2017.08.014

Papadokonstantakis S, Karka P, Kikuchi Y, Kokossis A (2016) Challenges for Model-Based Life Cycle Inventories and Impact Assessment in Early to Basic Process Design Stages. Elsevier Inc.

Portha J-F, Jaubert J-N, Louret S, Pons M-N (2010) Life Cycle Assessment Applied to Naphtha Catalytic Reforming. Oil Gas Sci Technol - Rev d’IFP Energies Nouv 65:793-805. doi: 10.2516/ogst/2010019

Bernstad Saraiva A (2017) System boundary setting in life cycle assessment of biorefineries: a review. Int J Environ Sci Technol 14:435-452. doi: 10.1007/s13762-016-1138-5

Serra P, Giuntoli J, Agostini A, et al (2017) Coupling sorghum biomass and wheat straw to minimise the environmental impact of bioenergy production. J Clean Prod 154:242-254. doi: 10.1016/j.jclepro.2017.03.208

SimaPro (2019). https://simapro.com/ (accessed 12 February 2019) 
TEAM (2019). https://ecobilan.pwc.fr/en/team.html (accessed 12 February 2019)

Thinkstep Gabi (2019). https://www.thinkstep.com/ (accessed 12 February 2019)

Tonini D, Hamelin L, Astrup TF (2016)a Environmental implications of the use of agro-industrial residues for biorefineries: application of a deterministic model for indirect land-use changes. GCB Bioenergy 8:690-706. doi: 10.1111 gcbb. 12290

Tonini D, Hamelin L, Alvarado-Morales M, Astrup TF (2016)b GHG emission factors for bioelectricity, biomethane, and bioethanol quantified for 24 biomass substrates with consequential life-cycle assessment. Bioresour Technol 208:123-133. doi: 10.1016/j.biortech.2016.02.052

Tumilar A, Sharma M, Milani D, Abbas A (2016) Modeling and Simulation Environments for Sustainable Low-Carbon Energy Production - A Review. Chem Prod Process Model 11:97-124. doi: 10.1515/cppm-2015-0035

Turner DA, Williams ID, Kemp S (2016) Combined material flow analysis and life cycle assessment as a support tool for solid waste management decision making. J Clean Prod 129:234-248. doi: 10.1016/j.jclepro.2016.04.077

Umberto (2019). https://www.ifu.com/en/umberto/lca-software/ (accessed 12 February 2019)

Wang Q-L, Li W, Gao X, Li S-J (2016) Life cycle assessment on biogas production from straw and its sensitivity analysis. Bioresour Technol 201:208-214. doi: 10.1016/j.biortech.2015.11.025

Yoshida H, Nielsen MP, Scheutz C, et al (2016) Long-Term Emission Factors for Land Application of Treated Organic Municipal Waste. Environ Model Assess 21:111-124. doi: 10.1007/s10666-015-9471-5

Zabaniotou A (2018) Redesigning a bioenergy sector in EU in the transition to circular waste-based Bioeconomy-A multidisciplinary review. J Clean Prod 177:197-206. doi: 10.1016/j.jclepro.2017.12.172

Zarrin B, Baumeister H (2014) Design of a Domain-Specific Language for Material Flow Analysis Using Microsoft DSL Tools. In: Proceedings of the 14th Workshop on Domain-Specific Modeling - DSM '14. ACM Press, New York, New York, USA, pp 23-28. doi: 10.1145/2688447.2688452 